\title{
Exergy Analysis of Rocket Systems
}

\author{
Andrew Gilbert; Dr. Bryan Mesmer, PhD \\ Industrial and Systems Engineering and Engineering \\ Management \\ The University of Alabama in Huntsville \\ Huntsville, AL
}

\author{
Dr. Michael D. Watson, PhD \\ Chief Engineers Office \\ System Engineering Management Office \\ NASA Marshall Space Flight Center \\ Huntsville, AL
}

\begin{abstract}
Exergy is defined as the useful work available from a system in a specified environment. Exergy analysis allows for comparison between different system designs, and allows for comparison of subsystem efficiencies within system designs. The proposed paper explores the relationship between the fundamental rocket equation and an exergy balance equation. A previously derived exergy equation related to rocket systems is investigated, and a higher fidelity analysis will be derived. The exergy assessments will enable informed, value-based decision making when comparing alternative rocket system designs, and will allow the most efficient configuration among candidate configurations to be determined.
\end{abstract}

Keywords-exergy; exergy analysis; rocket systems; system efficiency; attribute trade space; value-driven design

\section{INTRODUCTION}

In the past 110 years aerospace vehicle designs have evolved from two man design and manufacturing organizations to companies with over 170,000 employees [1] with more than 50 suppliers scattered across the globe [2]. The modern aerospace vehicles are complex systems consisting of many interrelated subsystems that are the result of a complex design process. The subsystems and components of these complex systems can be finely decomposed until small teams or groups can design them using appropriate disciplines and the related methods and techniques. For example, an aircraft's engine subsystem includes a turbine that has a component of a turbine blade. The turbine blade can be designed with knowledge of such disciplines as fluid dynamics and structural dynamics by a small group of people or even an individual. While individual components of the system can often be designed using classical techniques and existing databases, the integrated flight vehicle itself can pose a much more complicated design problem. Performance metrics and efficiency models of the different components that make up a system typically cannot directly be compared across disciplines. For example, the common performance metric of electrical demands of flight computers have little obvious relationship with the performance metric of lift to drag ratio typical of wing design. Exergy, defined as the useful work available from a system in a specified environment, provides a "common currency" useful for system-level optimization. Essentially, exergy provides a system attribute that can span disciplines, subsystems, and system decompositions to provide a common performance metric. Because the systems of an aerospace vehicle all depend on energy in some form, exergy assessment provides a useful tool for comparison between different system designs. Furthermore, exergy assessment can enable the comparison of subsystem efficiencies within a system design. This analysis will enable design efforts to be focused on the improvement of system efficiency based on subsystem efficiency [3].

This paper examines the analysis of exergy in rocket systems. The relationship between the fundamental rocket equation and an exergy equation is examined. Previously formed rocket system exergy analysis equation assumptions are discussed and a higher fidelity analysis is derived. Multiple examples are used to demonstrate the appropriateness of past assumptions for rocket system exergy and the error generated compared to that of the higher fidelity exergy analysis.

\section{BACKGROUND}

Value-Driven Design (VDD) is a systems engineering approach which relates the attributes of a system to a single numerical value that can be used to rank order design alternatives and aid in design decisions [4]. The mathematical means of relating the attributes to the value is in the value function [5]. Value functions are decomposable, for example a net present profit function can be decomposed to revenue and cost functions which can further be decomposed. In this sense the attributes that make up a system, such as the revenue, are also decomposable. As value functions are functions of attributes (and design variables), it is critical to properly identify the appropriate attributes and to calculate them accurately. A typical attribute of transportation systems is their efficiency, such as the miles per gallon fuel efficiency attribute that has recently been a primary sales point of automobiles. Exergy analysis provides a high fidelity means of determining the total efficiency of a system and its subsystems. The exergy attribute can be used directly as the value of the system to make decisions or in conjunction with other system attributes to form a higher level system value.

Exergy assessment is a synthesis of the first and the second laws of thermodynamics. The first law of 


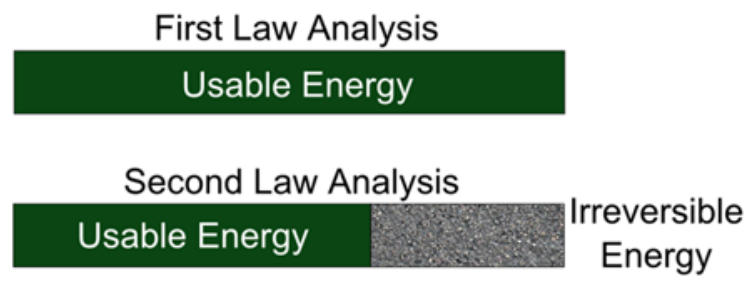

Figure 1: Visualization of irreversible energy and usable energy

thermodynamics states that energy must be conserved; it cannot be created or destroyed, only transformed from one form into another. The first law must be satisfied in order for a process to take place, but it does not ensure the process will actually occur [6]. The second law of thermodynamics introduces the state variable entropy, and explains the directionality of energy processes. A reversible (ideal) process is one in which a system can spontaneously restore itself to its original state. An irreversible (real) process requires additional energy transfers for a system to return to its original state. Entropy will always increase during irreversible processes [6]. Szargut defines exergy as "the amount of work obtainable when some matter is brought to a state of thermodynamic equilibrium with the common components of the natural surroundings by means of reversible processes..." [7]. Therefore the exergy, or usable energy, of a system can be assessed by using both the second and first laws of thermodynamics to analyze a system, as shown in figure 1.

Exergy has previously been used as a metric for a range of applications. One example of an exergy application has been as a general quality measure for resources used in production, such as food, forest products, and mineral ores [8]. In this application exergy accounts for both energy waste and material waste during industrial processes. In Thermoeconomics, exergy is used to evaluate the cost of different forms of energy, such as heating a home using coal versus electricity [9]. Exergy has previously been used in the analysis of power generation, such as coal-fired power plants [10], [11], combined-cycle plants [12], and nuclear power plants [13], [14]. In the comparison of coal power plants and nuclear power plants, exergy analysis allowed process inefficiencies to be better pinpointed than that of traditional energy analyses. Som and Datta reviewed the use of exergy analysis in gaseous, liquid, and solid fuel combustion [15]. More recently, exergy has been used to analyze the performance of hypersonic aircraft and hypersonic propulsion systems, such as scramjets [3], [16]. Cambreros and Moorhouse demonstrated the usefulness of exergy when analyzing, designing, and optimizing an aerospace vehicle [17]. The examples highlight the benefits of exergy analysis across a wide range of industries and applications.

An area of research that could benefit from exergy analysis but which has not been extensively researched is the application of exergy analysis to rocket systems. Past research [3] has examined rocket systems in methods similar to that of airplanes, using assumptions that are not always valid for extreme altitude vehicles. This paper examines the validity of these assumptions and modifications to the exergy analysis of rocket systems equation to enable improved design decisions when comparing design alternatives. System exergy, in aggregating the contributions of the rocket subsystems to the total system performance, provides a quantitative measure of the overall efficiency of the rocket as the means of comparing alternatives. This provides a basis for determining the most efficient configuration options early in the system design process.

\section{THEORY}

To perform an exergy analysis of a rocket system, assumptions based on the rocket equation are applied to a previous exergy model for aerospace vehicles [3]. The traditional rocket equation, used as a basis for the exergy equation, is given in (1) [18].

$$
\Delta V=\left[v_{2}+\left(p_{2}-p_{3}\right) / \dot{m}_{p}\right] \ln \frac{m_{0}}{m_{f}}
$$

where $\Delta \mathrm{V}$ is the ideal vehicle velocity increase (no external forces, such as drag or gravity), $p$ is pressure, $\dot{m}_{p}$ is mass flow rate of propellant, $\mathrm{m}_{0}$ is initial vehicle mass, $\mathrm{m}_{\mathrm{f}}$ is final vehicle mass, subscript 2 is the rocket nozzle exit condition, and subscript 3 is the free stream dead state. Equation (1) shows that a changing free stream dead state impacts the ideal velocity that can be achieved by a rocket.

Riggins [3] developed a model for calculating the irreversibilities of an aerospace vehicle across a mission, given in (2).

$$
\begin{gathered}
\left.H_{p} \Delta \text { (propellantmassused }\right)-\int_{\text {mission }} T_{i} d S_{\text {irr(total })} \\
=\Delta\left(m_{\text {veh }} \frac{v^{2}}{2}\right)+\int_{\text {mission }} m_{\text {veh }} g z
\end{gathered}
$$

where $H_{p}$ is the heating value of the propellant, $T_{i}$ is the free stream temperature, $S_{\text {irr(total })}$ is the total entropy due to irreversibilities, $\mathrm{m}_{\mathrm{veh}}$ is the mass of the vehicle, $\mathrm{v}$ is the velocity of the vehicle, $g$ is the acceleration due to gravity, and $\mathrm{z}$ is the altitude of the vehicle.

Equation (2) is a fundamental exergy balance equation. The first term on the left hand side is the exergy content of the expended propellant. The second term on the left hand side is the cumulative exergy loss associated with all irreversibilities (assuming constant $\mathrm{T}_{\mathrm{i}}$ ). The first term on the right hand side is the change in vehicle exergy due to kinetic energy. The second term on the right hand side is the change in exergy due to the potential energy of the vehicle. Primary assumptions in the formation of (2) from [3] are a thermally balanced vehicle (hence no heat transfer in the exergy balance 
equation), standard atmospheric conditions, and a constant acceleration due to gravity. The assumption of standard atmosphere also impacts the heating value used in the equation. The research in this paper examines the validity of these assumptions of the exergy analysis on rocket systems. Modified equations based off of the rocket equation (1) are compared with the results using the current exergy analysis equation for rockets (2).

\section{Methodology}

The Saturn V rocket (seen in Fig. 2) was a rocket system used by NASA during the Apollo and Skylab missions for delivery of men and equipment into space [19]. The Saturn $\mathrm{V}$ rocket system consists of three stages. At the end of each stage the used components are expended, followed by the ignition of the next stage. The stages of the rocket, a commonly used approach for space rockets, offer an opportune point at which to study the exergy available during a stage. In equation (2) developed previously, the change in mass, as well as the final and initial masses of the system, are important variables. The separation of vehicle stages from the portion of interest (the portion carrying the payload) offers unique challenges to traditional exergy analysis. These challenges are overcome by analyzing the exergy of the system in segments related to the stages. The Saturn V launch vehicle is used to investigate the error associated with different dead states assumed in the staging of the space craft, comparing the results with the use of standard atmosphere and gravitational constants for dead states used in [3]. This paper investigates any errors associated with the atmosphere properties as well as a changing acceleration due to gravity.

Riggins performed an exergy analysis using Saturn V launch vehicle data in [3]. This data is used with equation (2) to establish a baseline in order to compare higher fidelity models. The analysis is performed using the staging of the rocket as reference points. Each time the rocket drops a stage, equation

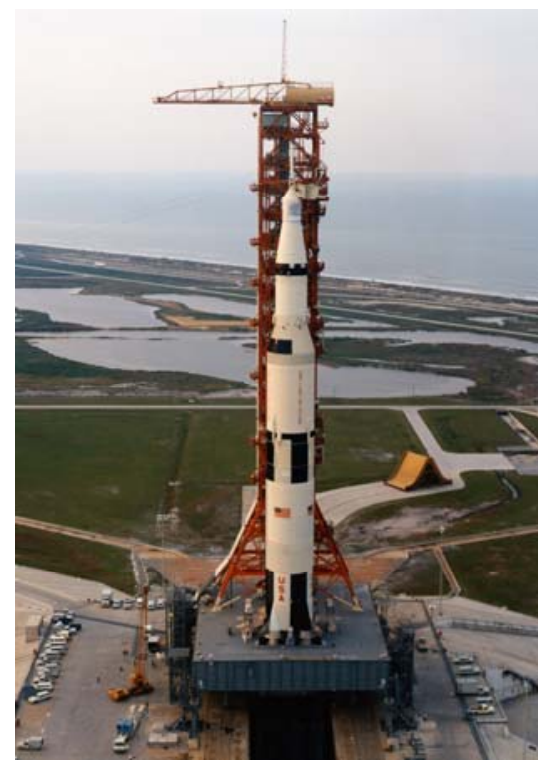

Figure 2. Saturn V Rocket [19]
(2) is used to calculate the exergy destruction for the current rocket configuration. The energies associated with each stage are then summed to assess the entire launch vehicle.

Two modifications are made to the analysis to achieve higher fidelity results. The first modification adjusts the parameters of enthalpy and gravity based on atmospheric temperature and altitude. The second modification expands the analysis to cover the entire flight trajectory of the launch vehicle.

Two other rocket systems are investigated in addition to the Saturn V. The Falcon 9 v1.1 is a two stage rocket designed by SpaceX. It is the first rocket completely developed in the $21^{\text {st }}$ century. The first stage consists of nine Merlin engines while the second stage consist of one Merlin vacuum engine. The Falcon 9 is used to deliver cargo to the International Space Station, and to deliver satellites to low earth or geosynchronous orbits. It is also designed to one day carry humans into space [20].

The Proton $\mathrm{M}$ is a Russian built three stage rocket. It is evolved from a 1965 rocket design, the UR-500, later nicknamed Proton. The Proton M can utilize an optional fourth stage, the Breeze M, for increased payloads beyond LEO. The Proton rocket family has been used to launch the Salyut and Mir space stations, as well as two of the first ISS components. It has also launched interplanetary payloads, such as the Russian lunar and Venus landers [21].

\section{A. Adjusted Parameters}

The heating value of propellant is equivalent to the heat of combustion of a chemical reaction, which is the difference between the standardized enthalpies of a chemical reaction's products and reactants. The heating value of a propellant is an estimate of $\mathrm{H}^{*}$, which is the change in chemical potential between the freestream air and the propellant in the tanks [3]. $\mathrm{H}^{*}$ is used in place of the heating value of the propellant and is adjusted based on the standard temperatures at increasing altitudes. This enthalpy value is adjusted by assuming a linear relationship with temperature, as shown in (3).

$$
\Delta h=C_{p} \Delta T(3)
$$

Gravity is adjusted in relation to altitude, as shown in (4).

$$
g_{h}=g_{0}\left(\frac{r_{e}}{r_{e}+z}\right)^{2}
$$

Where gh is the gravitational acceleration at altitude $\mathrm{z}$ above sea level, re is the mean radius of Earth, and $\mathrm{g} 0$ is the standard gravitational acceleration.

As a secondary comparison, gravity is also adjusted according to Newton's Law of Universal Gravitation, as shown in $(5)$.

$$
F=G \frac{m_{1} m_{2}}{r^{2}}(5)
$$

Where $F$ is the force between the two masses, $G$ is the gravitational constant, $\mathrm{m} 1$ is the mass of Earth, $\mathrm{m} 2$ is the mass 
Table 1. Saturn V - Stages w/ Constant Parameters

\begin{tabular}{|l|c|c|c|c|}
\hline \multirow{2}{*}{$\begin{array}{c}\text { Rocket } \\
\text { Stage }\end{array}$} & $\begin{array}{c}\text { Propellant } \\
\text { Energy } \\
\text { Expended } \\
(\boldsymbol{J})\end{array}$ & $\begin{array}{c}\text { Total Work } \\
\text { Due to } \\
\text { Kinetic } \\
\text { Energy (J) }\end{array}$ & $\begin{array}{c}\text { Total Work } \\
\text { Due to } \\
\text { Altitude } \\
\text { Change (J) }\end{array}$ & $\begin{array}{c}\text { Availability } \\
\text { Loss (J) }\end{array}$ \\
\hline S-I & $1.72 \times 10^{13}$ & $2.77 \times 10^{12}$ & $1.10 \times 10^{12}$ & $1.33 \times 10^{13}$ \\
\hline S-II & $5.28 \times 10^{12}$ & $2.28 \times 10^{12}$ & $5.04 \times 10^{11}$ & $2.50 \times 10^{12}$ \\
\hline S-IVB & $4.40 \times 10^{11}$ & $-8.65 \times 10^{11}$ & $9.86 \times 10^{08}$ & $1.30 \times 10^{12}$ \\
\hline Total & $2.29 \times 10^{13}$ & $4.18 \times 10^{12}$ & $1.61 \times 10^{12}$ & $1.71 \times 10^{13}$ \\
\hline
\end{tabular}

Table 2. Saturn V - Stages w/ Adjusted Parameters

\begin{tabular}{|l|c|c|c|c|}
\hline \multirow{2}{*}{$\begin{array}{c}\text { Rocket } \\
\text { Stage }\end{array}$} & $\begin{array}{c}\text { Propellant } \\
\text { Energy } \\
\text { Expended } \\
(\boldsymbol{J})\end{array}$ & $\begin{array}{c}\text { Total Work } \\
\text { Due to } \\
\text { Kinetic } \\
\text { Energy (J) }\end{array}$ & $\begin{array}{c}\text { Total Work } \\
\text { Due to } \\
\text { Altitude } \\
\text { Change (J) }\end{array}$ & $\begin{array}{c}\text { Availability } \\
\text { Loss (J) }\end{array}$ \\
\hline S-I & $1.72 \times 10^{13}$ & $2.77 \times 10^{12}$ & $1.08 \times 10^{12}$ & $1.33 \times 10^{13}$ \\
\hline S-II & $5.28 \times 10^{12}$ & $2.28 \times 10^{12}$ & $4.76 \times 10^{11}$ & $2.53 \times 10^{12}$ \\
\hline S-IVB & $4.40 \times 10^{11}$ & $-8.65 \times 10^{11}$ & $9.31 \times 10^{08}$ & $1.30 \times 10^{12}$ \\
\hline Total & $2.29 \times 10^{13}$ & $4.18 \times 10^{12}$ & $1.56 \times 10^{12}$ & $1.72 \times 10^{13}$ \\
\hline
\end{tabular}

Table 3. Saturn V - Across Altitude

\begin{tabular}{|l|c|c|c|c|}
\hline \multirow{2}{*}{$\begin{array}{c}\text { Rocket } \\
\text { Stage }\end{array}$} & $\begin{array}{c}\text { Propellant } \\
\text { Energy } \\
\text { Expended } \\
(\boldsymbol{J})\end{array}$ & $\begin{array}{c}\text { Total Work } \\
\text { Due to } \\
\text { Kinetic } \\
\text { Energy (J) }\end{array}$ & $\begin{array}{c}\text { Total Work } \\
\text { Due to } \\
\text { Altitude } \\
\text { Change (J) }\end{array}$ & $\begin{array}{c}\text { Availability } \\
\text { Loss (J) }\end{array}$ \\
\hline S-I & $1.72 \times 10^{13}$ & $2.77 \times 10^{12}$ & $1.08 \times 10^{12}$ & $1.33 \times 10^{13}$ \\
\hline S-II & $5.28 \times 10^{12}$ & $2.28 \times 10^{12}$ & $4.76 \times 10^{11}$ & $2.53 \times 10^{12}$ \\
\hline S-IVB & $4.40 \times 10^{11}$ & $-8.65 \times 10^{11}$ & $9.31 \times 10^{08}$ & $1.30 \times 10^{12}$ \\
\hline Total & $2.29 \times 10^{13}$ & $4.18 \times 10^{12}$ & $1.56 \times 10^{12}$ & $1.72 \times 10^{13}$ \\
\hline
\end{tabular}

of the rocket, and $\mathrm{r}$ is the distance between the centers of the two masses.

\section{B. Analysis Across Altitude}

The analysis is expanded across the entire flight profile to determine any errors associated with only assessing the staging points. The rocket's flight trajectory was discretized across altitude, and the exergy analysis was performed at each altitude step. This process was performed for each stage, and the energies were summed at the end to assess the entire rocket system.

\section{RESULTS}

The results from the baseline analysis are shown in Table 1. These results were calculated using the dead states of each stage of the Saturn V launch vehicle.
Table 4. Comparison of Analysis Methods on Saturn V

\begin{tabular}{|c|c|c|c|}
\hline \multirow{2}{*}{ Analysis Method } & \multicolumn{3}{|c|}{ Percentage of Expended Propellant } \\
Energy \\
\cline { 2 - 4 } & $\begin{array}{c}\text { Total Work } \\
\text { Due to } \\
\text { Kinetic } \\
\text { Energy (J) }\end{array}$ & $\begin{array}{c}\text { Total Work } \\
\text { Due to } \\
\text { Altitude } \\
\text { Change (J) }\end{array}$ & $\begin{array}{c}\text { Availability } \\
\text { Loss (J) }\end{array}$ \\
\hline $\begin{array}{c}\text { Saturn V - Constant } \\
\text { Parameters }\end{array}$ & $18.26 \%$ & $7.02 \%$ & $74.72 \%$ \\
\hline $\begin{array}{c}\text { Saturn V - Adjusted } \\
\text { Parameters }\end{array}$ & $18.26 \%$ & $6.81 \%$ & $74.94 \%$ \\
\hline $\begin{array}{c}\text { Saturn V-Across } \\
\text { Altitude w/ Adjusted } \\
\text { Parameters }\end{array}$ & $18.26 \%$ & $6.81 \%$ & $74.94 \%$ \\
\hline
\end{tabular}

Table 5. Comparison of Different Rocket Systems

\begin{tabular}{|c|c|c|c|}
\hline \multirow{2}{*}{ Rocket System } & \multicolumn{3}{|c|}{ Percentage of Expended Propellant } \\
Energy \\
\cline { 2 - 4 } & $\begin{array}{c}\text { Total Work } \\
\text { Due to } \\
\text { Kinetic } \\
\text { Energy (J) }\end{array}$ & $\begin{array}{c}\text { Total Work } \\
\text { Due to } \\
\text { Altitude } \\
\text { Change (J) }\end{array}$ & $\begin{array}{c}\text { Availability } \\
\text { Loss (J) }\end{array}$ \\
\hline Saturn V & $18.26 \%$ & $6.81 \%$ & $74.94 \%$ \\
\hline Falcon 9v1.1 & $13.12 \%$ & $5.76 \%$ & $81.12 \%$ \\
\hline Proton M & $4.66 \%$ & $1.83 \%$ & $93.51 \%$ \\
\hline
\end{tabular}

The results from the modified method using adjusted parameters are shown in Table 2. The heating value is adjusted based on the atmospheric temperature experienced at each staging point, and the gravity is adjusted based on the altitude of each staging point. The percent error associated with the availability loss using adjusted parameters is $0.28 \%$, and the percent error associated with total work due to altitude change is $3.13 \%$. There was no change in results due to using Newton's Law of Universal Gravitation, so only one data table is presented for adjusted parameters. However, Newton's Law of Universal Gravitation presents a method of analyzing deep space rockets, when multiple bodies will be applying gravitational forces to the rocket.

The results from running the analysis across the entire flight profile of the rocket are shown in Table 3. These results were calculated by discretizing across altitude, and by running the exergy analysis (2) at each altitude data point. There is no change when compared to using adjusted parameters at staging points.

Table 4 provides a comparison of the methods used to assess the exergy used by the Saturn V. The data is presented as percent of propellant energy used to achieve desired kinetic and potential energies, as well as the percentage of propellant energy used to overcome availability losses.

Two additional rocket systems were studied to show that exergy analysis can be used to generate preferences when rank ordering design decisions. The Falcon 9 [20] and the Proton M [22] were both analyzed across altitude using the adjusted parameters of temperature dependent enthalpy and altitude dependent gravity. The case study results are shown in Table 5. 


\section{DISCUSSION}

\section{A. Development of Multi-Fidelity Model}

To perform a comparison of equations, a baseline was established for the currently used exergy analysis equation (2). In [3], equation (2) was used to assess the performance of the Saturn V launch vehicle. The parameters used involve the appropriate masses, velocities, duration, and heating values at each of the vehicle's stages. The stages are an important aspect of space vehicles that must be accounted for, as mass is typically expelled from the main vehicle to lighten the craft and to allow for the next engine to run. The analysis from [3] shows that $74 \%$ of the expended propellant energy was necessary to overcome availability losses (irreversibilities). Only 19\% of the total propellant energy was used to achieve the desired kinetic energy, with the remainder used to achieve the desired potential energy [3]. These results were replicated by the authors using the parameters and equations. However, comparing equation (1) to the assumptions used in equation (2), we would expect different exergy results. The performance of a rocket system given by equation (1) shows that the assumptions used by equation (2) would not hold for a rocket system. A rocket experiences greater atmospheric condition changes and gravitational acceleration changes than aircraft. The developed methods indicate that the assumptions of standard atmosphere and constant gravitational acceleration result in minimal errors for the rocket systems examined. These assumptions are reasonable for atmospheric vehicles but not for vehicles where the exergy analysis is performed beyond the Earth's atmosphere.

This paper has shown that adjusted parameters based on atmospheric conditions and altitudes result in minimal improvements. For low earth orbit (LEO), analyzing the entire flight profile of a rocket holds no benefit over analyzing just the staging dead states. Therefore, rocket system designs for LEO applications can be compared using data at staging states. Errors resulting from gravity impacts would be expected for deep space missions, such as a mission to Mars. It is expected that analyzing the exergy destruction across the entire trajectory in conjunction with Newton's Law of Universal Gravitation would identify the errors associated with deep space missions.

Equation (1) was used to calculate the ideal velocity (highest achievable velocity without external forces, such as drag and gravity) of the Saturn V. The ideal velocity of the Saturn V was calculated to be approximately $10,000 \mathrm{~m} / \mathrm{s}$, compared to the actual burn out velocity of the vehicle, which was approximately $7,000 \mathrm{~m} / \mathrm{s}$. Actual velocity will always be lower than ideal velocity due to losses the vehicle must overcome. These losses are captured by applying exergy analysis to overall rocket performance.

\section{B. Role in Value Models}

Value-Driven Design (VDD) relates the attributes of a system to a single numerical value that can be used to rank order design alternatives and aid in design decisions. Value functions relate attributes to value and are based on the preferences of stakeholders. These functions can be decomposed into attributes, which can each be decomposed into further attributes.

A possible preference common in aerospace design is the desire for an elegant design. One mean by which elegance might be defined is through the efficiency of the system. This is a common desire held by engineers. A value function that would capture such a desire may be based on an attribute of exergy. Efficiency is a common desire or part of a desire, requiring a representation of efficiency in value functions. Due to this a meaningful representation is needed, such as the exergy analysis described in this paper.

\section{CONCLUSION}

This paper examined the use of airbreathing vehicle assumptions in the analysis of exergy for rocket systems. Assumptions based on the rocket equation were applied to a previously developed exergy model. The previous assumptions are seen to be valid for LEO applications, but further improvements may be needed for deeper space missions. This paper also compared three different rocket systems, the Saturn V, Falcon 9 v1.1, and the Proton M, by using the developed higher fidelity exergy model. The comparisons of different systems using exergy analysis provides a foundation to use exergy based efficiency as an attribute in VDD. Value functions incorporating efficiency will benefit from a thorough investigation of exergy such as the one explored in this paper.

\section{VIII.FUTURE WORK}

Future areas of research exist for the application of exergy analysis to rocket systems. A further understanding of the use of the model beyond LEO is required to apply exergy analysis to deep space rocket systems, such as NASA's Space Launch System. Furthermore, system level exergy values relate directly to subsystem exergy values. Future work will investigate the relationships between system and subsystem exergy analyses to aid in the identification of subsystems that will result in significant increases in efficiency. Future work will also investigate the decomposability of exergy into attributes for value modeling. The use of exergy in preference based rank ordering will be explored by applying exergy analysis to VDD principles.

\section{REFERENCES}

[1] “Boeing About Us,” Boeing About Us, Jul-2014. [Online]. Available:

http://www.boeing.com/boeing/companyoffices/aboutus /index.page. [Accessed: 17-Nov-2014].

[2] 'Boeing 787 Dreamliner Provides New Solutions for Airlines, Passengers," Boeing 787 Dreamliner Provides New Solutions for Airlines, Passengers. [Online]. Available:

http://www.boeing.com/boeing/commercial/787family/ background.page? [Accessed: 17-Nov-2014].

[3] J. A. Camberos and D. J. Moorhouse, Exergy Analysis and Design Optimization for Aerospace Vehicles and Systems, vol. 238. Reston, VA: American Institute of Aeronautics and Astronautics, 2011. 
[4] G. Richardson, J. Penn, and P. Collopy, "Value-centric analysis and value-centric design," in AIAA SPACE Conference and Exposition, 2010.

[5] P. D. Collopy and P. M. Hollingsworth, "Value-driven design," J. Aircr., vol. 48, no. 3, pp. 749-759, 2011.

[6] Y. A. Cengel, Introduction to Thermodynamics and Heat Transfer. McGraw-Hill Higher Education, 2008.

[7] J. Szargut, Exergy Method: Technical and Ecological Applications. WIT Press, 2005.

[8] R. U. Ayres, L. W. Ayres, and K. Martinás, "Exergy, waste accounting, and life-cycle analysis," Energy, vol. 23, no. 5, pp. 355-363, 1998.

[9] M. A. Rosen and I. Dincer, "Exergy-cost-energy-mass analysis of thermal systems and processes," Energy

Convers. Manag., vol. 44, no. 10, pp. 1633-1651, 2003.

[10] M. A. Habib and S. M. Zubair, "Second-law-based thermodynamic analysis of regenerative-reheat

Rankine-cycle power plants," Energy, vol. 17, no. 3, pp. 295-301, Mar. 1992.

[11] J. H. Horlock, J. B. Young, and G. Manfrida, "Exergy Analysis of Modern Fossil-Fuel Power Plants," J. Eng. Gas Turbines Power, vol. 122, no. 1, pp. 1-7, Jul. 1999.

[12] H.-Y. Kwak, D.-J. Kim, and J.-S. Jeon, "Exergetic and thermoeconomic analyses of power plants," Energy, vol. 28, no. 4, pp. 343-360, Mar. 2003.

[13] M. A. Rosen and D. S. Scott, "Energy and exergy analyses of a nuclear steam power plant," 1986.

[14] M. A. Rosen, "Energy- and exergy-based comparison of coal-fired and nuclear steam power plants," Exergy Int. J., vol. 1, no. 3, pp. 180-192, 2000.

[15] S. K. Som and A. Datta, "Thermodynamic irreversibilities and exergy balance in combustion processes," Prog. Energy Combust. Sci., vol. 34, no. 3, pp. 351-376, Jun. 2008.

[16] V. Amati, C. Bruno, D. Simone, and E. Sciubba, "Exergy analysis of hypersonic propulsion systems: Performance comparison of two different scramjet configurations at cruise conditions," Energy, vol. 33, no. 2, pp. 116-129, Feb. 2008.

[17] J. A. Camberos and D. J. Moorhouse, "Systems Engineering in Terms of Exergy," Int. J. Aerosp. Eng., vol. 2009, pp. 1-7, 2009.

[18] G. P. Sutton and O. Biblarz, Rocket propulsion elements. New York: John Wiley \& Sons, 2001.

[19] "Saturn V Moon Rocket," Boeing History. [Online]. Available:

http://www.boeing.com/boeing/history/boeing/saturn.pa ge. [Accessed: 12-Nov-2014].

[20] spacexcmsadmin, "Capabilities \& Services," SpaceX, 27-Nov-2012. [Online]. Available:

http://www.spacex.com/about/capabilities. [Accessed: 12-Feb-2015].

[21] "Proton Heritage," ILS International Launch Services Inc. [Online]. Available: www.ilslaunch.com/launchservices/ils-proton-breeze-m-launch-vehicle/protonheritage. [Accessed: 08-Feb-2015].
[22] 'Proton Launch System Mission Planner's Guide," LKEB-9812-1990, Jul. 2009. 